Bodo Bischoff (Berlin)

\title{
Zum Gedenken an Klaus Kropfinger (1930-2016)
}

„Und wie von alters her, im Stillen, Ein Liebewerk nach eignem Willen Der Philosoph, der Dichter schuf, So wirst du schönste Gunst erzielen: Denn edlen Seelen vorzufühlen Ist wünschenswertester Beruf."

In der abschließenden Strophe des mit „Vermächtnis“ überschriebenen Gedichts von Goethe bündeln sich einem Brennglas gleich Konzept und Teleologie eines erfüllten Forscherlebens. Klaus Kropfinger zitierte sie in einem seiner letzten Briefe kurz vor seinem Tod. Zur Lyrik, die er nicht nur umfänglich rezipierte und zu zitieren in der Lage war, sondern derer er sich auch selber als sehr persönliches Medium kunstfertig bediente, hatte er stets eine tief gegründete Affinität.

Nach dem Abitur (1948) musste er als Sohn eines Rechtsanwalts angesichts der Doktrin in der DDR zunächst über drei Jahre als Fräser in einer Fabrik arbeiten. Erst nach Ableistung dieser Auflage durfte er an der Hochschule für Musik Weimar (1951) mit dem Schulmusikstudium beginnen, aus dem er bald in das Klavier-Studium (Konzertfach) wechselte, das er 1956 mit dem Examen abschloss. Im selben Jahr flüchtete er in die BRD, um an den Universitäten von Bonn und Köln Musikwissenschaft, Kunstgeschichte, Romanistik, Philosophie und Ethnologie zu studieren. Von 1962-1966 gehörte er dem Editionskollegium der Neuen Beethoven-Gesamtausgabe an. Anschließend war er von 1966-1968 sowie 1971 Stipendiat der Thyssen Stiftung. Seine als habilitationsäquivalent gewertete Dissertation zur Beethoven-Rezeption Richard Wagners schloss er 1971 ab. Sie trug wesentlich dazu bei, dass die Rezeptionsforschung innerhalb der Musikwissenschaft zu einer ernst zu nehmenden Disziplin avancierte. Signifikant für die Strahlkraft dieser facettenreichen Studie ist ihre 1991 bei Cambridge University Press erschienene englische Übersetzung.

Von 1973 bis 1987 war er Professor für Musikwissenschaft an der Freien Universität Berlin. Anschließend erhielt er den Ruf auf den Lehrstuhl für Musikwissenschaft an der Universität Kassel, wo er 1995 emeritiert wurde. Seine Forschungs- und Lehrtätigkeit umfasste Themen vom Mittelalter bis in die Neuzeit mit einem Schwerpunkt von Arbeiten über Beethoven, Wagner und Nono. Er vertrat den Königsweg eines integralen Fachverständnisses, in dem ästhetische und strukturanalytische Reflexion, Skizzenforschung und Edition, biographische und kulturhistorische Forschung sowie Aufführungspraxis und Interpretation im Wandel ihrer historischen Kontexte einander wechselseitig durchdringen. Sein Doppelinteresse als Kunst- und Musikwissenschaftler führte ihn von 1989-1990 zu einem Forschungsaufenthalt an das Getty Center for the History of Art and the Humanities in Santa Monica. Sympathisch war seine skrupulöse Arbeitsweise, sein unermüdliches Streben, den Kern eines Problems zu erfassen und es zugleich in eine unverwechselbar ausgefeilte sprachliche Form zu gießen. Durch sein offenes Wissenschaftsverständnis, dem alles doktrinäre fern lag, war er für das fachliche und methodische Denken seiner Studierenden ein stets anregender und den Diskurs maßgeblich prägender Katalysator.

Klaus Kropfinger verstarb liebevoll betreut von seiner Ehefrau, Dr. Helga von Kügelgen, mit der er lebenslang einen intensiven fachlichen Austausch pflegte, nach schwerer Krankheit in seiner Wohnung in Berlin-Schöneberg. 